\title{
Egg pecking and puncturing behaviors in shiny and screaming cowbirds: effects of eggshell strength and degree of clutch completion
}

\author{
Natalia A. Cossa ${ }^{1} \cdot$ Diego T. Tuero ${ }^{1} \cdot$ Juan C. Reboreda $^{1} \cdot$ Vanina D. Fiorini $^{1}$
}

Received: 7 October 2016 /Revised: 21 February 2017 / Accepted: 24 February 2017

(C) Springer-Verlag Berlin Heidelberg 2017

\begin{abstract}
Shiny cowbirds (Molothrus bonariensis) are generalist brood parasites that use hosts varying in body and egg size. On the contrary, screaming cowbirds (M. rufoaxillaris), which are larger than shiny cowbirds, are host specialist that use mainly one host of similar body and egg size. Both parasites peck and puncture eggs when visiting nests. Through puncturing eggs, cowbirds can reduce the competition for food their chicks face (reduction of competition hypothesis), but the same behavior could also be a mechanism to enforce host to renest when nests are found late in the nesting cycle (farming hypothesis). Eggshell strength increases the difficulty to puncture eggs and therefore may modulate egg-pecking behavior. To test these hypotheses, we studied the effect of the degree of clutch completion and egg size on egg-puncturing behavior. Moreover, we evaluated if morphological differences between cowbird species and eggshell strength affected egg-pecking behavior. We presented captive females a nest with complete (four eggs) or incomplete (one egg) clutches of house wren (small egg size, low eggshell strength), chalk-browed mockingbird (large egg size, intermediate eggshell strength), or shiny cowbird (medium egg size, high eggshell strength). The proportion of nests with punctured eggs was similar for complete and
\end{abstract}

Communicated by M. Soler

Electronic supplementary material The online version of this article (doi:10.1007/s00265-017-2289-1) contains supplementary material, which is available to authorized users.

Vanina D. Fiorini

vfiorini@ege.fcen.uba.ar

1 Departamento de Ecología, Genética y Evolución \& IEGEBA-CONICET, Facultad de Ciencias Exactas y Naturales, Universidad de Buenos Aires, Pabellón II Ciudad Universitaria, Buenos Aires, Argentina incomplete clutches. Cowbirds punctured more eggs in complete than in incomplete clutches, but in complete clutches, they did not destroy the entire clutch. There were no differences in the egg-pecking behavior between cowbird species, which pecked more frequently the eggs with the strongest eggshell. Our findings are consistent with the reduction of competition hypothesis.

\section{Significance statement}

Brood parasitic birds do not build nests and raise their chicks. Instead, they lay eggs in nests of other species (hosts), which carry out all parental care. Some brood parasites, like the cowbirds, peck and puncture eggs when they visit host nests. This behavior may help to reduce the competition for food that their chicks face in the nest (reduction of competition hypothesis) or may enforce hosts to renest (farming hypothesis). We experimentally studied egg-pecking and egg-puncturing behaviors in the host generalist shiny cowbird and the host specialist screaming cowbird. We found that the degree of clutch completion and egg size modulate egg-puncturing behavior and eggshell strength modulates egg-pecking behavior. Our results indicate that by puncturing eggs, cowbirds reduce nest competition.

Keywords Brood parasitism · Farming hypothesis ·

Molothrus bonariensis $\cdot$ Molothrus rufoaxillaris $\cdot$ Reduction of competition hypothesis

\section{Introduction}

Obligate avian brood parasites depend entirely on their hosts for reproduction and, as a consequence of parasitism, hosts suffer a decrease of their reproductive success (Davies 2000). One common cost of parasitism is the reduction of host clutch size that parasites achieve by removing or puncturing 
eggs (Peer 2006). Egg removal may benefit the parasite female in several ways. It may provide nutritional benefits if the egg is eaten (Davies and Brooke 1988; Sealy 1992), enhance the incubation of the parasitic egg (Peer and Bollinger 1997, 2000), or enforce hosts to accept the parasite egg (Hoover and Robinson 2007). Besides, egg puncturing may improve the survival of parasite's offspring due to the reduction of competition for food with other chicks (reduction of competition hypothesis, Carter 1986; Mason 1986a; Soler et al. 1997) or by reducing the number of nestlings the parasite chick has to kill (Spottiswoode and Colebrook-Robjent 2007; Spottiswoode 2013). Moreover, when host nests are found late in the nesting cycle, by destroying the entire clutch, parasite females may induce hosts to renest, creating new opportunities for parasitism (farming hypothesis, Arcese et al. 1996).

The cowbirds (Molothrus spp.) are a monophyletic group with five extant brood parasitic species that spread across America (Lanyon 1992). Cowbirds reduce host clutch size through puncturing or removing eggs when visiting host nests (Ortega 1998). Despite several studies having tried to test experimentally the adaptive value of this behavior (Tuero et al. 2012a; Dubina and Peer 2013; Fiorini et al. 2014; Swan et al. 2015), we still do not fully understand why it has evolved or it is maintained. For the brown-headed cowbird (M. ater), evidence supports that egg removal enhances incubation efficiency of the parasitic egg (Peer and Bollinger 1997, 2000), while egg punctures enforce hosts to renest (i.e., nest farming) (Arcese et al. 1996; Swan et al. 2015). Farming a nest is an adaptive behavior when the nest is found with a complete clutch and incubation has started. In this circumstance, cowbirds cannot synchronize parasitism with host laying and parasitism would not be effective (i.e., lower hatchability and chick survival, Fiorini et al. 2009). Therefore, by manipulating hosts to start a new reproductive attempt, cowbirds create future opportunities for parasitism (Arcese et al. 1996). For nest abandon to occur, there must be an important reduction of the clutch (Rothstein 1982). Accordingly, Swan et al. (2015) found that brown-headed cowbirds destroy a higher proportion of eggs in nests with four eggs (a complete clutch not suitable to be parasitized) than in nests with two eggs (a clutch in the laying period, when cowbird still can synchronize parasitism with host laying). Evidence in support of the farming hypothesis was also found in the bronzed cowbird (M. aeneus) and the shiny cowbird (M. bonariensis) (Peer and Sealy 1999; Nakamura and Cruz 2000).

Egg puncture likely serves several functions and support of the competition reduction hypothesis has been found in shiny and screaming (M. rufoaxillaris) cowbirds (Astié and Reboreda 2009; De Mársico and Reboreda 2014; Fiorini et al. 2014; Gloag et al. 2014). Shiny cowbirds are extreme host generalists, with more than 260 reported hosts (Lowther 2016). Contrarily, screaming cowbirds are extreme host specialists. In most of its range, screaming cowbirds parasitize almost exclusively the baywing (Agelaioides badius), but in some areas, they also parasitize the chopi blackbird (Gnorimopsar chopi; Di Giacomo and Reboreda 2015), the brown-and-yellow marshbird (Pseudoleistes virescens; Mermoz and Fernández 2003), and the austral blackbird (Curaeus curaeus; Lowther 2016). Both cowbird species are sympatric in southern South America (Ortega 1998; BirdLife International and Handbook of the Birds of the World 2016) and have similar diet and habitat use, and when visiting host nests, they peck and puncture but do not remove eggs as brown-headed cowbirds do (Hoy and Ottow 1964; Fraga 1998). The level of competition the parasitic chick faces at the nest varies according to the number and size of nestmates. In nests of a small host, cowbird chicks outcompete host chicks for food (Tuero et al. 2007) whereas in nests of a large host, the opposite occurs (Astié and Reboreda 2009; Fiorini et al. 2009; Gloag et al. 2012). Accordingly, some studies have found that shiny cowbirds puncture more eggs in nests of a large host than in those of a small host (Fiorini et al. 2009; Tuero et al. 2012a). A large number of eggs at the nest the day of parasitism is a proxy of a high level of future competition for cowbird chicks (Carter 1986; Astié and Reboreda 2009; Fiorini et al. 2009; Gloag et al. 2012) as it represents (i) a large number of host chicks and (ii) an advanced stage of host laying. Therefore, in large clutches, it would be adaptive for female cowbirds to puncture more eggs, making the timing of parasitism less critical for the survival of the parasite chick (Carter 1986). As expected, the number of eggs punctured by shiny cowbirds increases with the number of host eggs (Tuero et al. 2012b; Fiorini et al. 2014). Nevertheless, differences in cowbird egg-puncturing behavior between and within hosts could also be explained by differences in the number of cowbird visits before the nest is parasitized (Gloag et al. 2013). With respect to screaming cowbirds, selection to recognize eggs based on size differences would not be expected because eggs of this parasite and its main host are similar in size (Fraga 1983).

The egg-pecking behavior, through which cowbirds achieve to puncture eggs, could be affected by different factors. Cowbird eggshells are thicker than those of their hosts and non-parasitic relatives (Picman 1989; Mermoz and Ornelas 2004). This gives cowbird eggs a high resistance to punctures (Picman and Pribil 1997; López 2013). Because the bill is sensitive and flexible (Zusi 1984), through egg-pecking, cowbirds could evaluate eggshell strength. If this were the case, female cowbirds may modulate their egg-pecking behavior according to eggshell strength, pecking at higher frequency or intensity eggs with thicker shells (Fiorini et al. 2014). Egg-pecking behavior could be also affected by morphological characteristics of the parasitic cowbird species. Screaming cowbirds have a larger $(10 \%)$ body mass (Reboreda et al. 1996) and shorter bill (Jaramillo and Burke 1999) than shiny cowbirds. Therefore, they could peck eggs with a higher strength and need fewer pecks to puncture an egg. 
The aim of this work was to evaluate the effect of number of eggs and egg size on egg-puncturing behavior of female shiny and screaming cowbirds and to assess if this behavior is consistent with the predictions of the reduction of competition or farming hypotheses. Moreover, we analyzed if egg-pecking behavior varied between cowbird species and if it was affected by eggshell strength. We presented captive females artificial nests containing clutches with differing characteristics (extent of clutch completion, egg size, and eggshell strength). Through these experiments, we took into account individual differences and controlled for variables that may influence it, such as differences in host defenses (Gloag et al. 2013) or nest characteristics. Under the farming hypothesis, we expected cowbirds to puncture eggs in complete clutches, but not in incomplete clutches, because they should only destroy eggs in nests not suitable for parasitism. Moreover, in complete clutches, cowbirds should puncture most eggs, because this would induce host to abandon the nest. Besides, under this hypothesis, egg size should not affect egg-puncturing behavior as cowbirds are not trying to eliminate more competitive chicks. On the contrary, under the reduction of competition hypothesis, we expected cowbirds to puncture eggs in complete and incomplete clutches because they should eliminate future competition for their chicks whatever the stage they have found the nest. Furthermore, at complete clutches, they should puncture some eggs to reduce competition but allow the host to continue with the nesting attempt not destroying most eggs. In addition, shiny but not screaming cowbirds (which are not expected to recognize eggs for their size) should increase egg-puncturing behavior at clutches containing large eggs. With respect to the egg-pecking behavior, stronger eggs should need more pecks to be punctured than weaker eggs. Finally, due to their morphological characteristics, screaming cowbirds should need a lower number of pecks to puncture an egg than shiny cowbirds.

\section{Methods}

\section{Subjects}

The study was carried out at Reserva El Destino, near the town of Magdalena, in Buenos Aires Province, Argentina $\left(35^{\circ} 08^{\prime} \mathrm{S}\right.$, $57^{\circ} 23^{\prime} \mathrm{W}$ ), during October-February 2010-2011 and 20112012. In this area, the main hosts of shiny cowbirds are the chalk-browed mockingbird (Mimus saturninus, hereafter mockingbird) and the house wren (Troglodytes aedon, hereafter wren) (Mason 1986b), while screaming cowbirds only parasitize the baywing (De Mársico and Reboreda 2010).

We captured 47 female shiny cowbirds (21 in 2010-2011 and 26 in 2011-2012) and 18 female screaming cowbirds (5 in 2010-2011 and 13 in 2011-2012) using walk-in traps and mist nets. After capture, we housed the birds in a laboratory located close to the capture site where they were kept in individual cages $(120 \mathrm{~cm} \times 40 \mathrm{~cm} \times 40 \mathrm{~cm})$ at room temperature with a natural light:dark cycle. Due to the limited availability of cages, we tested six females at the same time at most.

Females were randomly assigned to the different cages. During captivity, birds were visually isolated and had ad libitum access to millet and water. Each cage contained an empty, artificial open cup nest $(10 \mathrm{~cm}$ in diameter) situated at the cage's end opposite to the food and water containers. After an acclimation period of $24-48 \mathrm{~h}$, we started with the experimental sessions that were carried out between 06:00 and 12:00 hours. The experiment consisted of the presentation of eggs of (1) wrens, which are the smallest and have the weakest eggshell; (2) mockingbirds, which are the largest and have an intermediate eggshell strength; and (3) shiny cowbirds, which are intermediate in size and have the strongest eggshell. The objective of using cowbird eggs was testing the effect of eggs more difficult to puncture on egg-pecking behavior. The quantitative parameters of the eggs are given in Table 1. It was not possible to record data blind because our study involved focal animals in the field. Parasitic eggs were collected from mockingbird and wren nests. Mockingbird nests were found by focusing on individual activity and inspecting potential nesting sites within the territory of breeding pairs. Wren eggs were collected from nests built in nest boxes placed in the study site. All eggs were collected during the laying period (one egg per nest) or from nests abandoned during laying.

Cowbirds were kept in captivity an average of 7 days, and after the experiment, they were released in the same place they were captured. During 2010-2011, we did not record systematically whether cowbirds laid eggs in captivity, but in 2011-2012, we recorded 11 shiny cowbirds and seven screaming cowbirds that laid eggs. Due to the low sexual dimorphism of screaming cowbirds, individuals that did not lay eggs during the experiment were genetically sexed. For details, see Tuero et al. (2012b).

\section{Experimental procedure}

There were six experimental treatments: (1) one wren egg, (2) four wren eggs, (3) one shiny cowbird egg, (4) four shiny cowbird eggs, (5) one mockingbird egg, and (6) four mockingbird eggs. At the study site, host clutch size of the main hosts of shiny cowbirds (wrens and mockingbirds) and

Table 1 Characteristics of the three types of eggs used in the experiments (López 2013)

\begin{tabular}{llll}
\hline Species egg & Volume $(\mathrm{ml})$ & Strength $^{\mathrm{a}}(\mathrm{N})$ & Shell thickness $(\mu \mathrm{m})$ \\
\hline Shiny cowbird & 4.07 & 3.62 & 118 \\
Wren & 1.60 & 1.33 & 65 \\
Mockingbird & 5.70 & 2.20 & 94 \\
\hline
\end{tabular}

${ }^{a}$ Estimations performed through quasistatic punctures 
screaming cowbirds (baywings) is around four eggs (Fiorini and Reboreda 2006; Tuero et al. 2007; De Mársico and Reboreda 2008). Therefore, a nest with one egg indicates an incomplete clutch while a nest with four eggs indicates a complete clutch. Each female experienced a maximum of four treatments per day, which order was randomly assigned. Each treatment lasted $30 \mathrm{~min}$ and the interval between them was $60 \mathrm{~min}$. Birds received each treatment once, except in the cases at which the female did not respond (peck) during the $30 \mathrm{~min}$. In that case, the treatment was repeated up to three times. The treatments were video-recorded using microcameras connected to a video recorder (Lawmate PVR-1000 or PVR500 ECO), digital video camera SONY Handycam HDD (DCR-SR82), or digital camera SONY (DSC-H70). At the end of the treatment, we recorded the number of punctured (broken) eggs. We scored the videos back in the laboratory to count the number of pecks until the first (nests with four eggs) or the only (nests with one egg) egg of the clutch was punctured. When necessary, videos were viewed in slow motion to count pecks.

\section{Statistical analyses}

We used generalized linear mixed models (GLMM, Zuur et al. 2009; Logan 2010) with female as the random factor. We tested the effect of number of eggs in the nest (categorical variable: one or four eggs), egg type (categorical variable: wren, mockingbird, or cowbird eggs), parasite species (categorical variable: shiny or screaming cowbird), and the three double interactions on the following dependent variables: (1) proportion of nests with punctures (GLMM with binomial error distribution and logit link function), (2) number of punctured eggs (GLMM with zero inflated Poisson error distribution and log link function), and (3) number of pecks until the first egg was punctured (GLMM with negative binomial error distribution and log link function). We calculated the proportion of nests with punctures (variable 1) as the number of nests in which at least one egg was punctured over the total number of nests. For the analysis of number of punctured eggs, we included females that pecked in at least two treatments (range 2-6). Similarly, for the analysis of number of pecks until the first egg was punctured, we included females that punctured eggs in at least two treatments (range 2-6). We were unable to record the number of punctured eggs for one shiny cowbird, decreasing in one the number of individuals for that analysis. We estimated overdispersion, and in all analyses, the parameter was close to 1 , indicating that the models fitted their distribution. To analyze if nests with four eggs, cowbirds puncture few or many eggs, we used sign tests to compare the percentage of cases at which cowbirds punctured zero, one, or two eggs with the percentage of cases at which cowbirds punctured three or four eggs.
Statistical analyses were carried out using R software, version 2.15.3 (R Development Core Team 2013), and the glmmADMB R package (Skaug et al. 2014). All tests were two tailed, values are reported as means $\pm \mathrm{SE}$, and differences were considered significant at $P<0.05$. Figures were created using GraphPad Prism 6.02.

\section{Results}

Thirty-nine of 47 shiny cowbird females $(83 \%)$ pecked in at least one treatment and 28 of them (72\%) punctured at least one egg (Online Resource 1). Similarly, 17 of 18 screaming cowbird females $(94 \%)$ pecked in at least one treatment and 13 of them (76\%) punctured at least one egg. The time elapsed between the first and the last peck of the trial was $493 \pm 44 \mathrm{~s}$ (mean \pm SE, range $1-1763 \mathrm{~s}, n=158$ trials) for shiny cowbirds and $420 \pm 67 \mathrm{~s}$ (range 1-1760 s, $n=71$ trials) for screaming cowbirds.

\section{Egg-puncturing behavior}

\section{Proportion of nests with punctured eggs}

Number of eggs was not a significant predictor of the proportion of nests with punctured eggs (Table 2; Fig. 1a, b). Egg type and cowbird species were significant predictors of the proportion of nests with punctured eggs (Table 2). The proportion of nests with punctured eggs was higher in treatments with mockingbird or wren eggs than in those with shiny cowbird eggs (Fig. 2a, b). There were no differences in the proportion of nests with punctured eggs in treatments with wren and mockingbird eggs (estimate $=0.73 \pm 0.56, Z=1.31$, $P=0.19$, Fig. 2a, b). The proportion of nests with punctured eggs was higher in experiments with screaming cowbirds $(0.77 \pm 0.06)$ than in those with shiny cowbirds $(0.49 \pm 0.04$, Table 2).

\section{Number of punctured eggs}

Number of eggs, egg type, and cowbird species were significant predictors of the number of punctured eggs per treatment (Table 2). Shiny and screaming cowbirds punctured more eggs in nests with four eggs than in nests with one egg (Fig. 3a, b), and they punctured more mockingbird or wren eggs than shiny cowbird eggs (Fig. 4a, b). There were no differences in the number of wren and mockingbird eggs punctured (estimate $=0.24 \pm 0.19, Z=1.27, P=0.21$, Fig. $4 a, b)$. Screaming cowbirds punctured more eggs $(1.03 \pm 0.11)$ than shiny cowbirds $(0.65 \pm 0.07$, Table 2$)$.

In nests with four eggs, the percentage of cases at which cowbirds punctured three or four eggs was lower than that at which they punctured zero, one, or two eggs in all but one treatment (screaming cowbirds with wren eggs) (Table 3). 
Table 2 Estimates \pm SE, $Z$ values, and significance $(P)$ of predictor variables for (a) proportion of nests with punctured eggs, (b) number of punctured eggs, and (c) number of pecks until the first egg was punctured. Double interactions presented values of $P>0.05$ and they are not shown

\begin{tabular}{|c|c|c|c|c|}
\hline \multicolumn{2}{|l|}{ Response variable } & \multirow{2}{*}{$\begin{array}{l}\text { Estimate } \pm S E \\
0.61 \pm 0.75\end{array}$} & \multirow{2}{*}{$\frac{Z}{0.81}$} & \multirow{2}{*}{$\begin{array}{l}P \\
0.42\end{array}$} \\
\hline (a) Proportion of nests with punctured eggs & Intercept & & & \\
\hline & Number of eggs (4 eggs) & $0.35 \pm 0.4$ & 0.88 & 0.38 \\
\hline & Egg type (mockingbird eggs) & $1.38 \pm 0.46$ & 2.99 & 0.003 \\
\hline & Egg type (wren eggs) & $2.11 \pm 0.58$ & 3.63 & $<0.001$ \\
\hline & Cowbird species (shiny cowbird) & $-2.18 \pm 0.86$ & -2.55 & 0.01 \\
\hline \multirow[t]{5}{*}{ (b) Number of punctured eggs } & Intercept & $-0.77 \pm 0.26$ & -3 & 0.003 \\
\hline & Number of eggs (4 eggs) & $0.56 \pm 0.17$ & 3.38 & $<0.001$ \\
\hline & Egg type (mockingbird eggs) & $0.42 \pm 0.2$ & 2.11 & 0.03 \\
\hline & Egg type (wren eggs) & $0.66 \pm 0.21$ & 3.18 & 0.001 \\
\hline & Cowbird species (shiny cowbird) & $-0.51 \pm 0.24$ & -2.16 & 0.03 \\
\hline \multirow[t]{5}{*}{ (c) Number of pecks until the first egg was punctured } & Intercept & $2.49 \pm 0.24$ & 10.55 & $<0.0001$ \\
\hline & Number of eggs (4 eggs) & $-0.62 \pm 0.15$ & -4.06 & $<0.0001$ \\
\hline & Egg type (mockingbird eggs) & $-0.91 \pm 0.18$ & -4.94 & $<0.0001$ \\
\hline & Egg type (wren eggs) & $-1.01 \pm 0.2$ & -5.2 & $<0.0001$ \\
\hline & Cowbird species (shiny cowbird) & $0.27 \pm 0.26$ & 1.05 & 0.29 \\
\hline
\end{tabular}

\section{Egg-pecking behavior}

\section{Number of pecks until the first egg was punctured}

Cowbird species was not a significant predictor of the number of pecks until the first egg was punctured (Table 2, Fig. 5). Type and number of eggs affected the number of pecks until the first egg was punctured (Table 2). The number of pecks until the first egg was punctured was higher in nests with cowbird eggs than in those with wren or mockingbird eggs (Table 2), but there were no differences between nests with mockingbird and wren eggs (estimate $=-0.11 \pm 0.19, Z=-0.56, P=0.58$, Fig. $6 \mathrm{a}, \mathrm{b})$. The number of pecks until the first egg was punctured was higher in nests with one egg $(8.81 \pm 1.37)$ than in those with four eggs $(4.96 \pm 0.74$, Table 2$)$.

\section{Discussion}

\section{Egg-puncturing behavior: reduction of competition with host chicks or nest farming?}

\section{Effect of degree of clutch completion}

Shiny and screaming cowbirds punctured the same proportion of complete (four eggs) and incomplete (one egg) clutches. Moreover, in nests with four eggs, cowbirds punctured less than three eggs in most cases (86\%). These results are not consistent with the predictions of the nest farming hypothesis. Recently, Swan et al. (2015) performed experiments with captive brown-headed cowbird females in which they manipulated artificial nests with natural eggs. They found that the
Fig. 1 Proportion of nests with punctured eggs (mean $\pm \mathrm{SE}$ ) for shiny (a) and screaming (b) cowbird females, in nests with one or four eggs. Sample sizes are given inside the bars. Same letters indicate no significant differences $(P>0.05)$
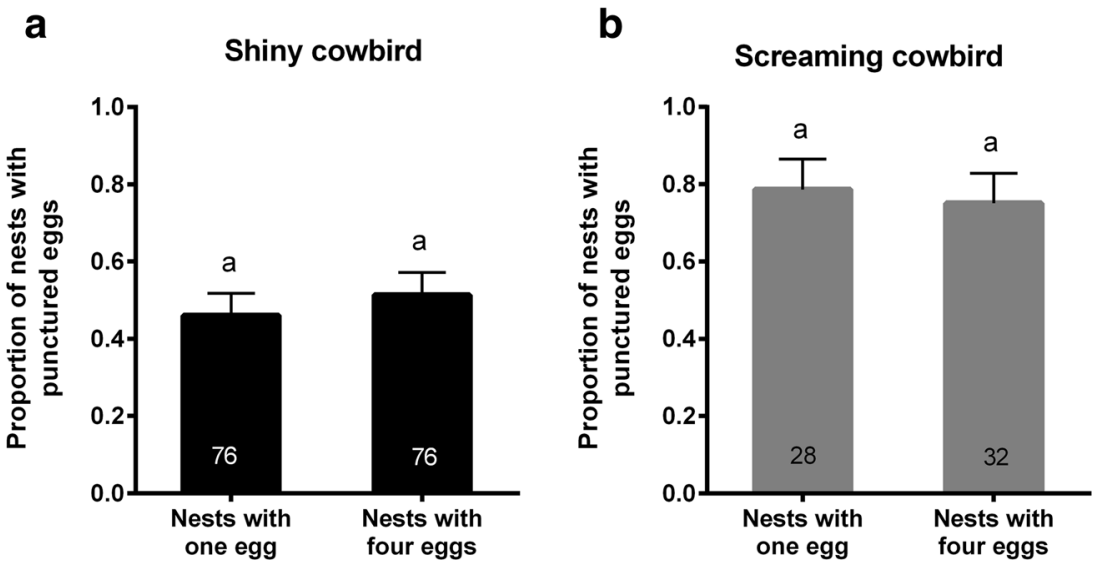
Fig. 2 Proportion of nests with punctured eggs (mean $\pm \mathrm{SE}$ ) for shiny (a) and screaming (b) cowbird females, in nests with house wren, cowbird, or mockingbird eggs. Sample sizes are given inside the bars. Different letters indicate significant differences $(P<0.05)$
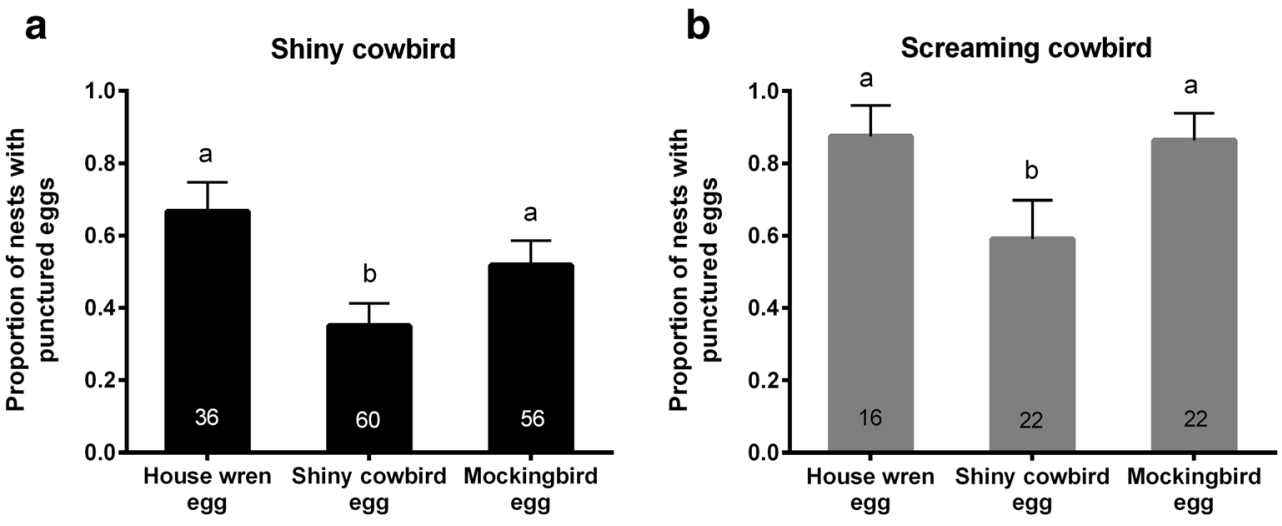

proportion of eggs destroyed was higher in nests with four eggs than in nests with two eggs, supporting the renesting hypothesis which predicts that nest content should be destroyed in complete clutches as they are not suitable to parasitize (Swan et al. 2015). In contrast with Swan et al. (2015) results, shiny and screaming cowbirds punctured eggs regardless the stage of the nest and in complete clutches, they frequently puncture only few eggs. It is worth to note that a female cowbird could find a nest early in the cycle, and if she is not physiologically prepared to parasitize it, she could destroy the clutch. Nevertheless, our experiments were designed with the assumption that cowbirds never farm early in the nesting cycle, supporting by findings from Swan et al. 2015. Previous studies in hosts of shiny cowbirds showed that the destruction of most eggs promotes nest abandonment (Massoni and Reboreda 1998; Tuero et al. 2007; VDF unpublished data). Therefore, the low proportion of punctured eggs in nests with four eggs is more consistent with the hypothesis of reduction of competition than with that of farming. Moreover, the fact that cowbird females that punctured eggs also laid eggs supports the idea that puncturing behavior is used for females under reproductive conditions.
These results are also compatible with previous studies conducted in hosts of screaming and shiny cowbirds that show indirect evidences against the farming hypothesis. For example, in baywings (screaming cowbird host), punctured eggs only appear in parasitized nests (De Mársico and Reboreda 2014). Moreover, in shiny cowbird hosts, the number of punctured eggs is similar or larger in parasitized than in nonparasitized nests (Massoni and Reboreda 1999; Fiorini and Reboreda 2006; Astié and Reboreda 2009). In addition, contrary to the results of studies on brown-headed and bronzed cowbirds that suggest that egg-puncturing behavior is used to force hosts to desert their nests (Peer and Sealy 1999), shiny and screaming cowbirds puncture eggs in association with parasitic events during host laying (Fiorini and Reboreda 2006; Astié and Reboreda 2009; Fiorini et al. 2009; Gloag et al. 2012; Tuero et al. 2012a) and video recordings show that these parasites peck host eggs and lay their own eggs during the same visit (De Mársico and Reboreda 2014; Fiorini et al. 2014). Although most studies on shiny cowbirds show that egg-puncturing behavior is associated with parasitism, it could be possible that in areas with high cowbird densities, egg punctures may reflect competitive interactions
Fig. 3 Number of punctured eggs (mean \pm SE) for shiny (a) and screaming (b) cowbird females, in nests with one or four eggs. Sample sizes are given inside the bars. Different letters indicate significant differences $(P<0.05)$
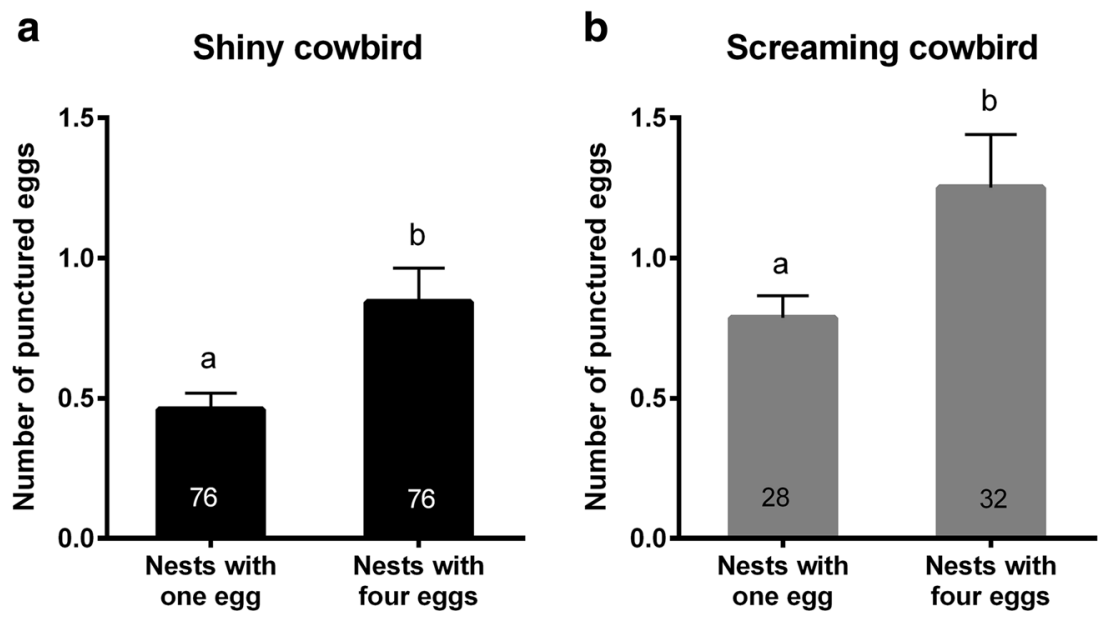
Fig. 4 Number of punctured eggs (mean \pm SE) for shiny (a) and screaming (b) cowbird females, in nests with house wren, cowbird, or mockingbird eggs. Sample sizes are given inside the bars. Different letters indicate significant differences $(P<0.05)$ a

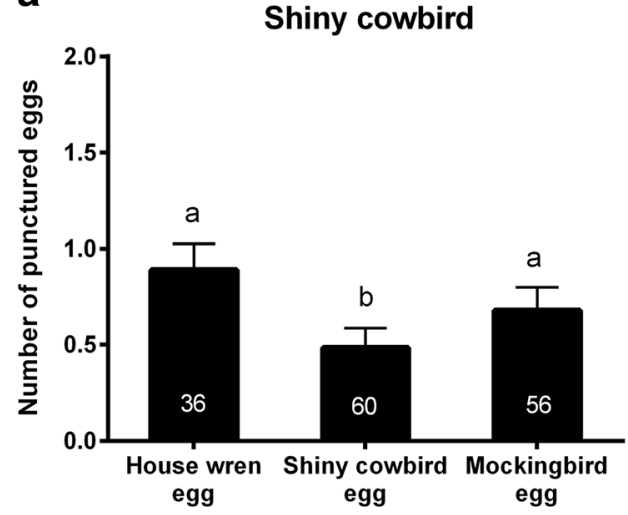

b

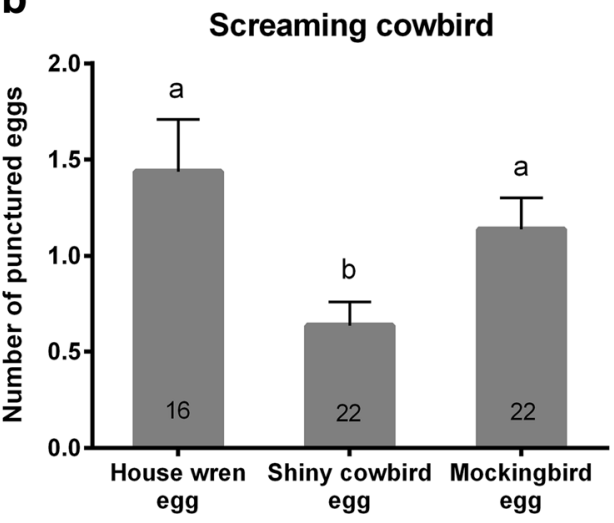

between cowbirds for parasitism opportunities (Nakamura and Cruz 2000). Under this scenario, punctures could be associated with nest abandon in most frequently parasitized hosts (Peer and Sealy 1999).

A nest with a large number of eggs is a predictor of a high number of future competitors for the parasitic chick and a more advanced nesting stage, which implies a lower hatchability and survival for the cowbird chick. Therefore, under the reduction of competition hypothesis, it would be adaptive for female cowbirds to puncture more eggs (although not the entire clutch) in nests with complete clutches (Tuero et al. 2012a). Accordingly, both cowbird species punctured more eggs in nests with four eggs than in those with one egg. It could seem obvious that more eggs were punctured in larger clutches, because there were more eggs to puncture. Nevertheless, cowbirds could have a fixed behavior and puncture always only one egg, no matter the size of the clutch. The present result is similar to that observed in shiny cowbirds in natural conditions, where the number of punctured eggs was higher in clutches with four eggs than in those with one egg (Fiorini et al. 2014). Also, the average number of punctured eggs in this study was similar to that reported for non-mobbed shiny cowbird females in natural mockingbird nests (Fiorini et al. 2014), which indicates that egg-puncturing behavior in our experimental condition is similar to that observed in natural conditions.

The destruction of more host eggs when nests have large clutches has also been observed in other brood parasite-host systems. The great spotted cuckoo (Clamator glandarius) destroys more host eggs in large than in small clutches of the magpie (Pica pica) (Soler et al. 1997) and the greater honeyguide (Indicator indicator) puncture more eggs in late parasitized clutches (Spottiswoode and Colebrook-Robjent 2007).

\section{Effect of egg type}

Under the competition reduction hypothesis, parasite females should puncture more eggs when they represent greater competition for food during the nestling period. Accordingly, for shiny cowbirds, we expected that they would puncture large eggs more frequently than small ones. In regard to screaming cowbirds, we did not expect that egg size would influence puncturing behavior, as they parasitize almost exclusively one host which has eggs similar in size to those of screaming cowbirds. However, we found that both cowbird species punctured the large (mockingbird) and the small (wren) eggs at similar frequencies while the intermediate eggs (cowbird)

Table 3 Mean \pm SE of the percentage of cases in which shiny cowbirds and screaming cowbirds punctured zero, one, or two eggs ( $0-2$ eggs) and 3 or 4 eggs (3-4 eggs), in nests with four eggs of different egg types. The sample size $(N), Z$ value, and significance $(P)$ for each test are shown

\begin{tabular}{|c|c|c|c|c|c|c|}
\hline \multirow[t]{2}{*}{ Species } & \multirow[t]{2}{*}{ Type of egg } & \multicolumn{2}{|c|}{ Mean \pm SE } & \multirow[t]{2}{*}{$N$} & \multirow[t]{2}{*}{$Z$} & \multirow[t]{2}{*}{$P$} \\
\hline & & 0-2 eggs & $3-4$ eggs & & & \\
\hline \multirow[t]{3}{*}{ Shiny cowbird } & Wren & $88 \pm 8$ & $12 \pm 8$ & 17 & 2.91 & $<0.01$ \\
\hline & Mockingbird & $90 \pm 6$ & $10 \pm 6$ & 29 & 4.09 & $<0.0001$ \\
\hline & Shiny cowbird & $90 \pm 6$ & $10 \pm 6$ & 30 & 4.2 & $<0.0001$ \\
\hline \multirow[t]{3}{*}{ Screaming cowbird } & Wren & $63 \pm 18$ & $37 \pm 18$ & 8 & 0.35 & 0.72 \\
\hline & Mockingbird & $83 \pm 11$ & $17 \pm 11$ & 12 & 2.02 & 0.04 \\
\hline & Shiny cowbird & 100 & 0 & 12 & 3.18 & $<0.01$ \\
\hline
\end{tabular}




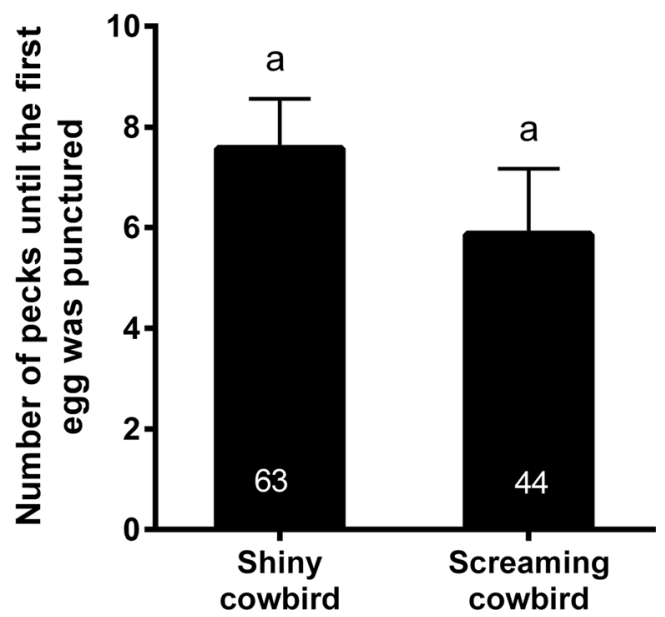

Fig. 5 Number of pecks (mean \pm SE) inflicted by shiny cowbird and screaming cowbird females until the first egg of the nest was punctured. Sample sizes are given inside the bars. Same letters indicate no significant differences $(P>0.05)$

were punctured the least. These results indicate that differences between wrens and mockingbirds in the number of punctured eggs per event of parasitism found in field studies could be the result of the difficulty of cowbird females to puncture eggs in the small nest cavity of wrens (Fiorini et al. 2009; Tuero 2010). Besides, female shiny cowbirds could be host specialist at the individual level (Mahler et al. 2007; Domínguez et al. 2015) with females that parasitize wrens puncturing less than those that parasitize mockingbirds. In this case, because we used the same females in all treatments, we would not expect to find differences in egg-puncturing behavior between treatments, but rather between females depending on the host they use.

\section{Egg-pecking behavior}

Shiny and screaming cowbirds are two Neotropical parasites that differ markedly in the degree of host specialization
(Ortega 1998). Screaming cowbirds, although they are larger than shiny cowbirds, needed a similar number of pecks to puncture eggs. Here, we estimated the difficulty that cowbirds face when they try to puncture eggs by counting the number of pecks until the egg was punctured. We found that cowbird eggs, which have the thickest and strongest eggshell of the three egg types, received more pecks until being punctured, than host eggs, from both cowbird species. Similar to our results, Spottiswoode and Colebrook-Robjent (2007) found that the greater honeyguide put more effort when trying to damage host eggs with thicker eggshells. Their estimation of parasite effort was number of puncture holes in the egg, because not all the holes pierced the shell. Likewise to what we showed for shiny and screaming cowbirds, they concluded that egg-destruction behavior is adjusted in an adaptive fashion.

Finally, the number of pecks required to puncture an egg was higher in nests with one egg than in those with four eggs. This result indicates that other variables, such as the pecking intensity, could modulate cowbird behavior. Thus, the presence of a large number of eggs in the nest could be a more intense stimulus for females that may peck harder to puncture the eggs when competition for food at the nest is expected to be higher.

\section{Conclusions}

Our experiments allowed us to control for individual differences between parasitic females and isolate the effect of clutch characteristics from other variables that may influence eggpuncturing behavior in natural conditions, such as interactions with hosts defending their nests or with other cowbird females visiting the nest simultaneously (Gloag et al. 2013). Our study shows that because cowbirds puncture eggs in incomplete and complete clutches and in the last case, they did not puncture many eggs, this behavior seems adapted to reduce future nestling competition instead of enforce renesting. Moreover,
Fig. 6 Number of pecks (mean \pm SE) inflicted by shiny (a) and screaming (b) cowbird females until the first egg of the nest was punctured, in nests with house wren, cowbird, or mockingbird eggs. Sample sizes are given inside the bars. Different letters indicate significant differences $(P<0.05)$
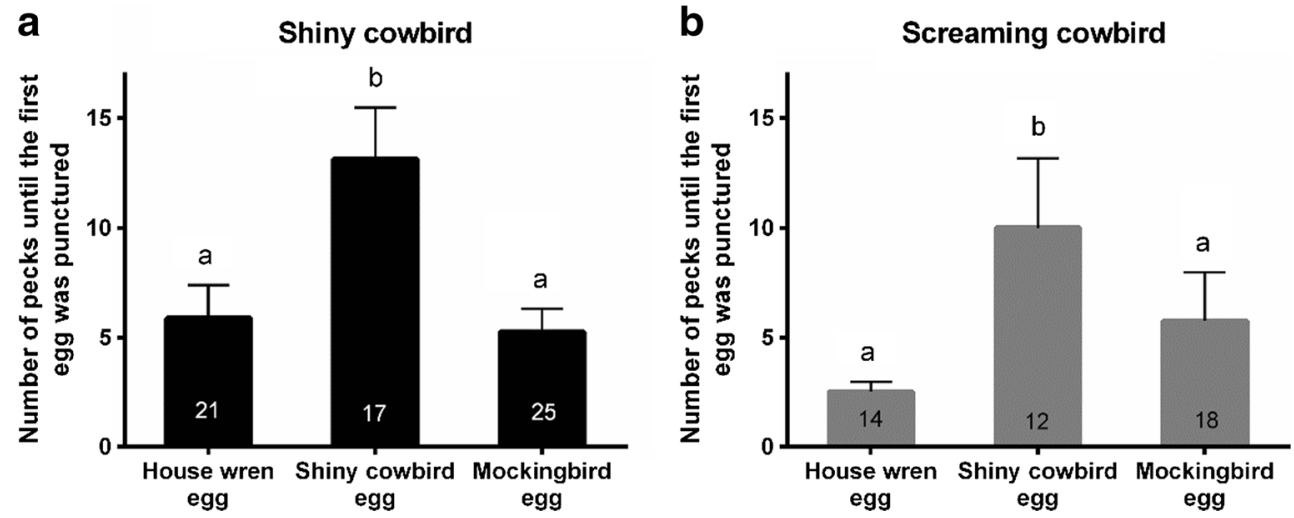
eggshell strength modulates the egg-pecking behavior of both cowbird female species, in a similar way. It remains to be determined if the modulation of egg-pecking and eggpuncturing behaviors showed by shiny and screaming cowbirds is shared with other species in the clade and how the interaction of host and parasitic life history traits (Servedio and Hauber 2006) modified these behaviors that seem to have a different function depending on the cowbird species.

Acknowledgments We thank "Elsa Shaw de Pearson Foundation" for supporting our fieldwork at Reserva El Destino. We are grateful to Brian Peer for thoughtful comments that contributed to the improvement of the manuscript. We also thank three anonymous referees and Manuel Soler who provided their helpful comments on a previous version of the manuscript. This work was supported by grants of the Agencia Nacional de Promoción Científica y Tecnológica and the University of Buenos Aires. DTT, JCR, and VDF are research fellows of Consejo Nacional de Investigaciones Científicas y Técnicas (CONICET).

\section{Compliance with ethical standards}

Conflict of interest The authors declare that they have no conflict of interest.

Ethical approval All procedures performed in studies involving animals were in accordance with the ethical standards of the institution or practice at which the studies were conducted. All work complied with the Argentinean Law for the Conservation of Wild Fauna (Ley Nacional de Fauna 22421/81) and was conducted with the authorization from the Organismo Provincial de Desarrollo Sostenible, Argentina (Permit number 202/12-O.P.D.S.).

\section{References}

Arcese P, Smith JN, James NM, Hatch MI (1996) Nest predation by cowbirds and its consequences for passerine demography. P Natl Acad Sci USA 93:4608-4611

Astié AA, Reboreda JC (2009) Function of egg punctures by shiny cowbird in parasitized and unparasitized creamy-bellied thrush nests. $\mathrm{J}$ Field Ornithol 80:336-343

BirdLife International and Handbook of the Birds of the World (2016) Molothrus bonariensis and Molothrus rufoaxillaris. The IUCN Red List of Threatened Species. Version 2016-3, http://maps.iucnredlist. org $/ \mathrm{map} . \mathrm{html}$ ?id=22724345, http://maps.iucnredlist.org $/ \mathrm{map} . \mathrm{html}$ ? id $=22724342$

Carter MD (1986) The parasitic behavior of the bronzed cowbird Molothrus aeneus in south Texas USA. Condor 88:11-25

Davies NB (2000) Cuckoos, cowbirds and other cheats. T. \& A.D, Poyser

Davies NB, Brooke MDL (1988) Cuckoos versus reed warblers: adaptations and counteradaptations. Anim Behav 36:262-284

De Mársico MC, Reboreda JC (2008) Egg-laying behavior in screaming cowbirds: why does a specialist brood parasite waste so many eggs? Condor 110:143-153

De Mársico MC, Reboreda JC (2010) Brood parasitism increases mortality of bay-winged cowbird nests. Condor 112:407-417

De Mársico MC, Reboreda JC (2014) High frequency but low impact of brood parasitism by the specialist screaming cowbird on its primary host, the baywing. Emu 114:309-316
Di Giacomo AG, Reboreda JC (2015) Reproductive success of the specialist brood parasite screaming cowbird in an alternative host, the chopi blackbird. Auk 132:16-24

Domínguez M, de la Colina MA, Di Giacomo AG, Reboreda JC, Mahler B (2015) Host switching in cowbird brood parasites: how often does it occur? J Evol Biol 28:1290-1297

Dubina KM, Peer BD (2013) Egg pecking and discrimination by female and male brown-headed cowbirds. J Ornithol 154:553-557

Fiorini VD, Reboreda JC (2006) Cues used by shiny cowbirds (Molothrus bonariensis) to locate and parasitise chalk-browed mockingbird (Mimus saturninus) nests. Behav Ecol Sociobiol 60:379-385

Fiorini VD, Tuero DT, Reboreda JC (2009) Shiny cowbirds synchronize parasitism with host laying and puncture host eggs according to host characteristics. Anim Behav 77:561-568

Fiorini VD, Gloag R, Reboreda JC, Kacelnik A (2014) Strategic egg destruction by brood parasitic cowbirds? Anim Behav 93:229-235

Fraga RM (1983) The eggs of the parasitic screaming cowbird (Molothrus rufoaxillaris) and its host, the bay-winged cowbird (M. badius): is there evidence for mimicry? J Ornithol 124:187-193

Fraga RM (1998) Interactions of the parasitic screaming and shiny cowbirds (Molothrus rufoaxillaris and M. bonariensis) with a shared host, the bay-winged cowbird (M. badius). In: Rothstein SI, Robinson SK (eds) Parasitic birds and their hosts: studies in coevolution. Oxford University Press, New York, pp 173-193

Gloag R, Tuero DT, Fiorini VD, Reboreda JC, Kacelnik A (2012) The economics of nestmate-killing in avian brood parasites: a provisions trade-off. Behav Ecol 23:132-140

Gloag R, Fiorini VD, Reboreda JC, Kacelnik A (2013) The wages of violence: mobbing by mockingbirds as a frontline defence against brood parasitic cowbirds. Anim Behav 86:1023-1029

Gloag R, Fiorini VD, Reboreda JC, Kacelnik A (2014) Shiny cowbirds share foster mothers but not true mothers in multiply parasitized mockingbird nests. Behav Ecol Sociobiol 68:681-689

GraphPad Software Inc (2007) GraphPad Prism, version 6.02. GraphPad Software Inc., San Diego, https://www.graphpad.com/scientificsoftware/prism/

Hoover JP, Robinson SK (2007) Retaliatory mafia behavior by a parasitic cowbird favors host acceptance of parasitic eggs. P Natl Acad Sci USA 104:4479-4483

Hoy G, Ottow J (1964) Biological and oological studies of the molothrine cowbirds (Icteridae) of Argentina. Auk 81:186-203

Jaramillo A, Burke P (1999) New world blackbirds: the icterids. Princeton University Press, Princeton

Lanyon SM (1992) Interspecific brood parasitism in blackbirds (Icterinae): a phylogenetic perspective. Science 255:77-79

Logan M (2010) Biostatistical design and analysis using R: a practical guide. Wiley, West Sussex

López A (2013) Comparative analysis of the eggshell characteristics of the parasitic species (genus Molothrus) and their main hosts. Undergraduate thesis, University of Buenos Aires, Buenos Aires

Lowther PE (2016) Lists of victims and hosts of the parasitic cowbirds. The Field Museum, https://www.fieldmuseum.org/sites/default/ files/plowther/2014/09/24/cowbird_hosts-17sep2014.pdf

Mahler B, Confalonieri VA, Lovette IJ, Reboreda JC (2007) Partial host fidelity in nest selection by the shiny cowbird (Molothrus bonariensis), a highly generalist avian brood parasite. J Evol Biol 20:1918-1923

Mason P (1986a) Brood parasitism in a host generalist, the shiny cowbird: I. The quality of different species as hosts. Auk 103:52-60

Mason P (1986b) Brood parasitism in a host generalist, the shiny cowbird: II. Host selection. Auk 103:61-69

Massoni V, Reboreda JC (1998) Costs of brood parasitism and the lack of defenses on the yellow-winged blackbird-shiny cowbird system. Behav Ecol Sociobiol 42:273-280 
Massoni V, Reboreda JC (1999) Egg puncture allows shiny cowbirds to assess host egg development and suitability for parasitism. Proc R Soc Lond B 266:1871-1874

Mermoz ME, Fernández GJ (2003) Breeding success of a specialist brood parasite, the screaming cowbird, parasitizing an alternative host. Condor 105:63-72

Mermoz ME, Ornelas JF (2004) Phylogenetic analysis of life-history adaptations in parasitic cowbirds. Behav Ecol 15:109-119

Nakamura TK, Cruz A (2000) The ecology of egg-puncture behaviour by shiny cowbird in southwestern Puerto Rico. In: Smith JNM, Cook TL, Rothstein SI, Robinson SK, Sealy SG (eds) Ecology and management of cowbirds and their hosts: studies in the conservation of North American passerine birds. University of Texas Press, Austin, pp $178-186$

Ortega C (1998) Cowbirds and other brood parasites. The University of Arizona Press, Tucson

Peer BD (2006) Egg destruction and egg removal by avian brood parasites: adaptiveness and consequences. Auk 123:16-22

Peer BD, Bollinger EK (1997) Explanations for the infrequent cowbird parasitism on common grackles. Condor 99:151-161

Peer BD, Bollinger EK (2000) Why do female brown-headed cowbirds remove host eggs? A test of the incubation efficiency hypothesis. In: Smith JNM, Cook TL, Rothstein SI, Robinson SK, Sealy SG, Ehrlich PR (eds) Ecology and management of cowbirds and their hosts: studies in the conservation of North American passerine birds. University of Texas Press, Austin, pp 187-192

Peer BD, Sealy SG (1999) Parasitism and egg puncture behaviour by bronzed and brown-headed cowbirds in sympatry. Stud Avian Biol $18: 235-240$

Picman J (1989) Mechanism of increased puncture resistance of eggs of brown-headed cowbirds. Auk 106:577-583

Picman J, Pribil S (1997) Is greater eggshell density an alternative mechanism by which parasitic cuckoos increase the strength of their eggs? J Ornithol 138:531-541

R Development Core Team (2013) R: a language and environment for statistical computing. R Foundation for Statistical Computing, Vienna http://www.r-project.org

Reboreda JC, Clayton NS, Kacelnik A (1996) Species and sex differences in hippocampus size between parasitic and non-parasitic cowbirds. Neuroreport 7:505-508
Rothstein SI (1982) Successes and failures in avian egg and nestling recognition with comments on the utility of optimality reasoning. Am Zool 22:547-560

Sealy SG (1992) Removal of yellow warbler eggs in association with cowbird parasitism. Condor 94:40-54

Servedio MR, Hauber MR (2006) To eject or to abandon? Life history traits of hosts and parasites interact to influence the fitness payoffs of alternative anti-parasite strategies. J Evol Biol 19:1585-1594

Skaug H, Fournier D, Bolker B, Magnusson A, Nielsen A (2014) Generalized linear mixed models using AD model builder. R package version 0.8.0, http://glmmadmb.r-forge.r-project.org/

Soler M, Soler JJ, Martínez JG (1997) Great spotted cuckoos improve their reproductive success by damaging magpie host eggs. Anim Behav 54:1227-1233

Spottiswoode CN (2013) A brood parasite selects for its own egg traits. Biol Lett 9:20130573

Spottiswoode CN, Colebrook-Robjent JF (2007) Egg puncturing by the brood parasitic greater honeyguide and potential host counteradaptations. Behav Ecol 18:792-799

Swan DC, Zanette LY, Clinchy M (2015) Brood parasites manipulate their hosts: experimental evidence for the farming hypothesis. Anim Behav 105:29-35

Tuero DT (2010) Flexibilidad comportamental del Tordo Renegrido (Molothrus bonariensis) al parasitar diferentes hospedadores. $\mathrm{PhD}$ thesis, University of Buenos Aires, Buenos Aires

Tuero DT, Fiorini VD, Reboreda JC (2007) Effects of shiny cowbird Molothrus bonariensis parasitism on different components of house wren Troglodytes aedon reproductive success. Ibis 149:521-529

Tuero DT, Fiorini VD, Reboreda JC (2012a) Do shiny cowbird females adjust egg pecking behavior according to the level of competition their chicks face in host nests? Behav Proccess 89:137-142

Tuero DT, Fiorini VD, Mahler B, Reboreda JC (2012b) Shiny cowbird Molothrus bonariensis egg size and chick growth vary between two hosts that differ markedly in body size. J Avian Biol 43:1-7

Zusi RL (1984) A functional and evolutionary analysis of rhynchokinesis in birds. Smithsonian Institution Press, Washington

Zuur AF, Ieno EN, Walker NJ, Saveliev AA, Smith GM (2009) Mixed effects models and extensions in ecology with R. Springer, New York 